University of Wollongong

Research Online

Faculty of Social Sciences - Papers (Archive) Faculty of Arts, Social Sciences \& Humanities

2013

\title{
A hitchhiker's guide to assessing sedentary behaviour among young people: Deciding what method to use
}

Louise L. Hardy

University of Sydney, louiseh@health.usyd.edu.au

Andrew P. Hills

Griffith University

Anna Timperio

Deakin University

Dylan Cliff

University of Wollongong, dylanc@uow.edu.au

David Lubans

University of Newcastle

See next page for additional authors

Follow this and additional works at: https://ro.uow.edu.au/sspapers

Part of the Education Commons, and the Social and Behavioral Sciences Commons

Research Online is the open access institutional repository for the University of Wollongong. For further information contact the UOW Library: research-pubs@uow.edu.au 


\title{
A hitchhiker's guide to assessing sedentary behaviour among young people: Deciding what method to use
}

\begin{abstract}
To provide a user's guide for selecting an appropriate method to assess sedentary behaviours among children and adolescents. While recommendations regarding specific instruments are not provided, the guide offers information about key attributes and considerations for objective (accelerometry; inclinometers; direct observation; screen monitoring devices) and subjective (self-report; parent report; and time use diaries/logs) approaches to assess sedentary behaviour Attributes of instruments and other factors to be considered in the selection of assessment instruments include: population (age); sample size; respondent burden; method/delivery mode; assessment time frame; physical activity information required (data output); data management; measurement error; cost (instrument and administration) and other limitations. Expert consensus among members of the Australasian Child and Adolescent Obesity Research Network's (ACAORN) Physical Activity and Sedentary Behaviour Special Interest Group. We developed decision flow charts to assist researchers and practitioners select an appropriate method of assessing sedentary behaviour, identified attributes of each method and described five real-life scenarios to illustrate considerations associated with the selection of each method of measurement. It is important that researchers, practitioners and policy makers understand the strengths and limitations of different methods of assessing sedentary behaviour among youth, and are guided on selection of the most appropriate instrument/s to suit their needs.
\end{abstract}

\section{Keywords}

among, method, young, deciding, people, hitchhiker, guide, assessing, sedentary, behaviour

\section{Disciplines}

Education | Social and Behavioral Sciences

\section{Publication Details}

Hardy, L. L., Hills, A. P., Timperio, A., Cliff, D., Lubans, D., Morgan, P. J., Taylor, B. J. \& Brown, H. (2013). A hitchhiker's guide to assessing sedentary behaviour among young people: Deciding what method to use. Journal of Science and Medicine in Sport, 16 (1), 28-35.

\section{Authors}

Louise L. Hardy, Andrew P. Hills, Anna Timperio, Dylan Cliff, David Lubans, Philip J. Morgan, Barry J. Taylor, and Helen Brown 
1 A hitchhiker's guide to assessing sedentary behavior among young people: Deciding what

2 method to use

3

$4 \quad$ Running title: Assessing sedentary behavior among young people

6 Louise L Hardy ${ }_{1}$ Andrew P Hills, 2 Anna Timperio,, 3 Dylan Cliff, 4 David Lubans,, 5 Philip J

7 Morgan,5 Barry J Taylor6, Helen Brown $\mathrm{H}_{3}$

8

9 1 Prevention Research Collaboration, University of Sydney, Sydney Australia

$10 \quad 2$ Centre for Nutrition and Exercise, Mater Medical Research Institute and Griffith Health

11 Institute, Griffith University, Brisbane, Australia

$12{ }_{3}$ Centre for Physical Activity and Nutrition Research, Deakin University, Burwood, Australia

134 Interdisciplinary Educational Research Institute, Faculty of Education, University of

14 Wollongong, Wollongong, Australia

155 Priority Research Centre in Physical Activity and Nutrition, School of Education, University

16 of Newcastle, Newcastle, Callaghan Campus, Australia

176 Department of Women's and Children's Health, Dunedin School of Medicine, University of

18 Otago, Dunedin, New Zealand

19

20 Correspondence to:

21 Louise L Hardy PhD

22 Prevention Research Collaboration,

23 Level 2, K25 Medical Foundation Building, University of Sydney, NSW Australia 2006

24 Phone: +6129036 3295; Facsimile: +6129036 3184

25 Email: louise.hardy@sydney.edu.au

26 Total word count (manuscript): 2998 Abstract 206; Tables: 2; Figures: 1 


\section{Abstract}

30 Objective To provide a user's guide for selecting an appropriate method to assess sedentary 31 behaviors among children and adolescents

32 Design While recommendations regarding specific instruments are not provided, the guide offers information about key attributes and considerations for objective (accelerometry;

34 inclinometers; direct observation; screen monitoring devices) and subjective (self-report;

35 parent report; and time use diaries/logs) approaches to assess sedentary behaviour 36 Attributes of instruments and other factors to be considered in the selection of assessment 37 instruments include: population (age); sample size; respondent burden; method/delivery 38 mode; assessment time frame; physical activity information required (data output); data management; measurement error; cost (instrument and administration) and other limitations.

40 Methods Expert consensus among members of the Australasian Child and Adolescent 41 Obesity Research Network's (ACAORN) Physical Activity and Sedentary Behavior Special 42 Interest Group.

43 Results We developed decision flow charts to assist researchers and practitioners select an appropriate method of assessing sedentary behavior, identified attributes of each method and described five real-life scenarios to illustrate considerations associated with the selection of each method of measurement.

Conclusions It is important that researchers, practitioners and policy makers understand the strengths and limitations of different methods of assessing sedentary behaviour among youth, and are guided on selection of the most appropriate instrument/s to suit their needs.

Keywords: sitting, screen time, measurement, methodology, children, 


\section{Introduction}

In recent decades, significant societal changes have created a reduced demand for physical activity with a profound resultant impact on the behavior of children and youth. ${ }^{1}$ Physical inactivity has been described as the biggest public health problem of our time. ${ }^{2 ; 3}$ There is strong evidence that physical activity is associated with numerous health benefits in youth ${ }^{4}$ and, similarly, that excessive sedentary behavior is likely to be independently related to a number of health-related conditions. ${ }^{5 ; 6}$ However, considerably more research is required to assess the benefits of reducing sedentary behavior, for example sitting less and standing more ${ }^{7}$ and the nature of sedentary behaviors tracking across the life course. ${ }^{8}$

Despite the apparent simplicity of the term, sedentary behavior is complex and not limited to a single behavior. ${ }^{9: 10}$ Time spent in sedentary behavior is distinct from lack of physical activity and, sedentary behaviors have unique behavioral constructs that have independent relationships to various health outcomes. ${ }^{11 ; 12}$ The importance of defining sedentary behavior and using the term consistently is illustrated by the fact that many studies which purport to address 'sedentary' behavior incorrectly assume individuals who are less active or do not meet recommended physical activity guidelines are sedentary. Rather, these individuals are 'insufficiently active', or 'inactive' if no physical activity is reported.

Sitting is the predominant sedentary behavior, but the term 'sedentary' has typically referred to any activity which does not increase resting energy expenditure appreciably above the resting metabolic rate (i.e., 1.0-1.5 metabolic equivalent units (METs)). ${ }^{13}$ It is also important to distinguish sedentary behavior from the energy expenditure of light-intensity physical activity (1.5-2.9 METs $)^{10}$. The most common sedentary activities include watching television (TV), playing video/computer games, surfing the Internet, reading, and playing a musical instrument. $^{14}$ 
80

81

Measurement of sedentary behavior is notoriously challenging as it requires an understanding of which behaviors are being undertaken, along with the context and the duration. In young people, a substantial amount of time is spent watching TV, however, this alone fails to capture the diversity of sedentary behaviors. ${ }^{9} \mathrm{~A}$ wide range of measures have been used to quantify TV viewing, including direct observation, self/proxy and real-time data capture, ${ }^{9}$ but considerable work is needed in this area. ${ }^{15}$ Recent systematic reviews of sedentary behavior measures highlighted the poor validity and reliability of many of the existing measures. ${ }^{6 ; 16}$ Further, the health consequences of sedentariness among youth have also been reported, ${ }^{6 ; 16}$ and linked to weight status and adverse metabolic profiles crosssectionally ${ }^{17-19}$ and prospectively. ${ }^{20 ; 21}$

Sedentary behavior is a relatively new area in health behavior research and there is a need to expand the evidence-base to better understand the epidemiology and health consequences, and determine effective intervention strategies. ${ }^{22 ; 23}$ The evidence must come from accurate measurement, and while there is scope for the improvement of measures of sedentary behavior in children and adolescents, there is currently a wide variety of approaches being utilized. ${ }^{15 ; 16}$ There is currently no guide detailing the characteristics and discussing the suitability of common measures to assist researchers and practitioners interested in measuring this behavior. The purpose of this paper is to provide a user's guide for selecting methods to assess sedentary behavior among children and adolescents.

\section{Methods}

In 2011, members of the Australasian Child and Adolescent Obesity Research Network's (ACAORN) Measurement of Physical Activity and Sedentary Behaviors Special Interest Group met to discuss how best to assist other stakeholders in child health who may be interested in measuring sedentary behavior among children and adolescents. The first step of this process was to undertake a systematic review to identify the validity and reliability of common methods used to measure sedentary behavior in young people. ${ }^{16}$ The second step 
108 was to highlight the decision making process that researchers and practitioners need to

109 consider when measuring sedentary behavior in young people, such as deciding on the type

110 of measurement instrument, the purpose of the assessment, and the practical

111 considerations.

115 Figure 1 illustrates the two methods (i.e., objective and subjective) used to assess sedentary

116 behavior in young people and the potential cost and sample size associated with each

117 measurement method. Each method comprises different instruments, and the key attributes

118 and the limitations and practical considerations of each instrument are listed in Tables 1 and

1192 2, respectively.

121 Objective measures of sedentary time may include motion devices (inclinometer,

122 accelerometer), observation (direct, video) and other electronic devices specifically designed

123 to measure electronic media use or screen time (ST). The primary reason for selecting

124 objective measures is to minimise measurement error, however objective measures are

125 typically more costly and therefore more likely to be used when assessing smaller numbers

126 of children, although large funded trials may also consider objective measures.

128 The limitation of motion devices is their inability to provide contextual information (i.e., setting

129 and type of activity). Accelerometers have traditionally been used to measure physical

130 activities rather than measuring sedentary time. There is, however, some evidence that

131 information on sedentariness (includes standing) can be reasonably determined from

132 accelerometers (i.e., cut point $<100 \mathrm{cpm}$ ). ${ }^{24 ; 25}$ More recently inclinometers, which assess

133 anatomical position in three planes (lying, sitting, standing) and postural changes

134 (sitting/standing) are being explored as a method to measure sedentary time in children. A 
135 limitation is that inclinometers, which are taped or strapped to the thigh, maybe

136 uncomfortable to wear for prolonged periods.

138 An additional consideration regarding motion devices is individual compliance; typically,

139 these small devices are worn for approximately one week, and can pose a degree of

140 participant burden, which may result in missing data when the device is not worn. Further,

141 there are times when these devices may malfunction, leading to a loss of data. While there

142 has been an increase in use of motion devices to measure sedentary time, a significant

143 research gap is the lack of standardised monitoring protocols (e.g., wear time) and data

144 reduction strategies (e.g., which algorithm).

146 Observation methods entail an observer recording participants' activities while watching the

147 subject. This may be completed by a trained individual directly observing the child or

148 indirectly by videoing the child. The benefit of using video recording is that multiple views

149 potentially improve objectivity and aspects of behavior can be reviewed. Irrespective, both

150 observation methods require systematic recording of observations. This may be achieved

151 using a simple observation method where the observer has a list to record the child's

152 posture, the domain (or setting) and the activity. It is worth noting that in some jurisdictions,

153 employing observation methods may be prohibited by institutional ethics committees.

Tables $1 \& 2$ about here

157 Subjective measures rely on self-report, or in the case of children aged $<12$ years, proxy

158 reporting by a third party (usually a parent). Subjective measures are generally cheaper so

159 are therefore often used in the assessment of larger groups, but may also be selected for

160 smaller groups when budgetary constraints prevail. A significant benefit of self/proxy report

161 methods is that contextual information can be collected which allows the researcher to

162 examine a broad range of sedentary behaviors, or specific sedentary activities such as ST 
163 passive transport. It is worth noting that while self-report measures may provide reliable

164 estimates of sedentary behavior or ST, their validity remains largely untested ${ }^{16}$. The major

165 limitation of self/proxy report is the potential for significant measurement error. Logs/diaries,

166 where the participant prospectively records the main activity undertaken during a specified

167 time interval (e.g., 30 minute blocks) have the potential to reduce measurement error, but

168 this method carries considerable respondent burden and is not appropriate for younger age

169 groups. Furthermore, because all activities are recorded, this method requires the extraction

170 of sedentary activities.

172 Scenarios The following scenarios have been selected to represent a range of

173 circumstances and should be read in conjunction with Figure 1 and Tables 1 and 2 which

174 provide greater detail to help guide the most appropriate choice of instrument(s).

175

176 Scenario A: Screen time intervention among preschoolers; Researchers plan to design and

177 evaluate the potential efficacy of a 12-week intervention to reduce ST in children aged 2-3

178 years in the home setting. Children will be randomised as a family unit to either an

179 intervention or control group. ST will be assessed among approximately 80 children (40 in

180 each group) at baseline and at 3-month post-intervention time points. The aims of this

181 research are to (i) determine if the intervention results in reduced total ST at home and, (ii)

182 determine duration by each screen type.

184 In this scenario, the researchers are assessing changes in children's ST using a randomised 185 controlled trial (RCT) design. Key outcomes of interest are the duration and context of the ST 186 participation at home. The sample comprises children who are too young to self-report, and 187 the study requires details of types of ST behavior. Objective measurement using

188 inclinometers or accelerometers are not appropriate as these methods will not provide the 189 context of the behavior or whether the sedentary time was ST or other sedentary behaviours. 
190 An appropriate approach is a parent proxy questionnaire using recall over a certain number

191 of days.

193 The number of days that represent an accurate estimate of habitual ST behaviors in this age

194 group and in this setting is unknown, and will depend on day-to-day variations in the home

195 context. Ideally, weekday and weekend day ST should be captured. However, despite

196 recognised limitations, parent proxy self-report recall instruments can be used to provide an

197 estimate of minutes spent in ST and assess compliance with guidelines and determine the

198 types of ST in which children engage.

Scenario B School-based RCT to reduce sitting during school class-time; Traditional classroom teaching techniques predominantly involve children being seated for sustained

202 periods. Evidence among adults suggests that sustained sitting may be detrimental to health 203 and that interrupting sitting time may reduce such risks. ${ }^{26}$ Researchers have planned a 6204 month RCT to test strategies to reduce classroom sitting in primary school children through 205 alternative teaching practices. The RCT involves two classes within each year level at six 206 schools (three control and three intervention schools), and approximately 300 students.

208 To determine the effectiveness of the intervention, researchers must detect changes in time 209 spent 'sitting' during class time between baseline and post-intervention. Key considerations

210 in the selection of appropriate measurement instruments include: the age of the participants,

211 the need to detect behavior within particular periods, the need to differentiate sitting from

212 other postures, potential burden to participants and minimisation of class disruption. In this

213 scenario, self-report measures may be inappropriate due to participant age (cognitive

214 limitations). Proxy-reports by teachers may also be inappropriate as they would only provide

215 group-level information rather than data about individuals. The use of self-report logs/diaries

216 may be burdensome during class-time, may disrupt class activities and could result in

217 reactivity. Accelerometry may also be inappropriate because they quantify 'movement' and 
218 do not provide any postural information. Low movement counts are indicative of limited

219 movement and not necessarily 'sitting'.

221 In this scenario, inclinometers and direct observation may be the most appropriate measurement tools. Inclinometers enable researchers to determine time spent sitting or lying (based on postural information), can be worn over long periods (e.g., one week) and

224 allow researchers to extract data from specific periods of interest (e.g., class times). Direct observation would provide the same 'information' with the additional opportunity to value-add by documenting specific behaviors undertaken in each posture (e.g., reading, writing, art, craft, etc). However, direct observation may result in reactivity as participants know they are being observed, and may be costly given the number of observations that would be required (each period across the school day for each class at each school) on multiple school days.

230 Further, the number of days of observations required is not established.

Scenario C: Treatment program for overweight/obese primary school children; A researcher is seeking to evaluate the effects of a 10-week family-centred sedentary behavior reduction

234 intervention on adiposity in overweight/obese 8- to 12-year-old children. The feasibility study 235 is a single-arm experiment involving 30 overweight/obese children with assessments of 236 sedentary behavior taken pre- and post-intervention, and the researcher wants to determine 237 if the intervention reduced children's sedentary time (i) overall daily and (ii) outside of school 238 hours.

240 For this intervention, the researcher needs to selects an instrument that is both accurate and 241 objective, and sensitive enough to detect the hypothesised changes in sedentary time.

242 Although the sample size is relatively small, direct observation would not be feasible because 243 it is likely that the children attend different schools, and because the researcher is also 244 interested in understanding the effects of the intervention on sedentary time outside of school hours. Self-report questionnaires offer a cost-effective option, but the assessments would be 
246 vulnerable to recall-bias because of the age of the participants. Parent-proxy reports would 247 also not be recommended because their estimates might be influenced by social desirability 248 bias and this could result in under-reporting of the behavior, or parents' understanding of the 249 desired effects of the intervention might result in under-reporting at post-test. It would also be 250 difficult to accurately assess children's total sedentary time, which occurs in many settings 251 and contexts and not always in the presence of parents.

253 An objective measure is recommended and monitoring devices worn on the body, such as 254 inclinometers or accelerometers, would be most suitable. The use of an inclinometer would 255 allow the researcher to examine time spent in different postures, and from this changes in 256 sitting/lying time as a result of the intervention could be evaluated. If accelerometers are 257 chosen, the researcher can apply age-appropriate cut-points to determine sedentary time.

258 The real-time data acquisition from objective monitoring devices would allow the researcher

259 to specifically examine sedentary time that occurs outside of school hours, in addition to 260 children's overall or total sedentary time per day.

Scenario D: Primary prevention of adolescent screen time in clinical settings; A general practitioner (GP) is concerned about the metabolic profile of an obese adolescent patient 264 presenting markedly overweight and with obvious signs of insulin resistance. During the 265 consultation the GP ascertains from the adolescents' parents and the adolescent that the 266 adolescent spends most of their time sitting on the couch playing e-games, watching 267 TV/DVDs.

269 Access to adolescent obesity management clinics is limited, and because the GP has a 270 small, busy practice is unable to provide on-going long consultations to the adolescent. The 271 GP decides that the best management strategy will be based on regular brief counselling 272 consultations that incorporate goal setting. The adolescent's parents are asked to help the 
273 adolescent set realistic ST reduction goals and to help monitor progress towards reducing

274 ST

276 Objective measures are not suitable for several reasons. Firstly, motion sensors do not capture contextual information and, the cost of motion sensors is prohibitive to the practice budget. Furthermore, the GP does not have the time and expertise to interpret the data

279 collected by objective instruments. Rather, the most feasible line of intervention is for the GP

280 to ask the adolescent to complete a time use diary, or suitable structured questionnaire, 281 about their ST.

This baseline information will identify the duration spent on ST and the time of day spent on

ST. The GP can use this information to help the adolescent set realistic goals aimed at reducing ST. The GP can monitor the adolescent's progress towards reducing ST at ongoing consultations for the monitoring the obese adolescents' progress.

Scenario E: Population prevalence of screen time among adolescents; Health and education professionals have concerns about non-school recreational ST among adolescents. In order to determine whether investments should be allocated to develop a school-based

291 intervention to encourage adolescents to reduce their ST, the first step is to ascertain how 292 prevalent ST is, and whether there are sociodemographic differences in teenagers' ST. To determine the population prevalence, a large sample of adolescents (i.e., several hundred)

294 from a range of high school years, across different educational sectors, and geographical 295 and socioeconomic areas is required to determine population estimates which are 296 generalisable.

298 In this scenario, objective measures such as accelerometers and inclinometers are 299 inappropriate for several reasons. First and foremost, objective measures do not provide 300 contextual information, so will not discriminate between ST activities, or other sitting 
301 behaviours, therefore self-report is the most desirable method of measurement. Unlike

302 younger children, adolescents are capable of self-report, albeit recall can be affected by

303 social desirability, and estimates of time are subject to large error. Questionnaires have the

304 ability to discriminate between ST activities and to determine habitual non-school ST on

305 week and weekend days. In school environments, questionnaires can be administered either 306 as pen and paper, or via computers/smart boards.

308 A significant issue to consider when asking students to report ST activities is the concept of 309 multi-tasking. For example, an adolescent may play on their computer while watching TV -

310 so during the administration of the questionnaire it is important to instruct respondents to

311 allocate the time proportionally spent on each screen activity. An alternative method to 312 measure ST behavior is with time use diaries/log, or ecological momentary assessment

313 (EMA), where respondents report activities undertaken during a specified time interval. A

314 limitation of this method is that all activities are reported, generating large volumes of data

315 from which ST data are extracted.

\section{Concluding remarks}

318 Sedentariness is a multi-faceted construct and is not considered a single behavior or the

319 opposite of physical activity. Given recent evidence highlighting the health-related

320 consequences that are independently associated with time spent in sedentary behaviors, the

321 accurate measurement of sedentary behavior is particularly important. However,

322 measurement is complex and requires an understanding of context, duration and which

323 behaviors are being undertaken. No single, currently available assessment tool captures and

324 describes every aspect of sedentary behavior. Objective measures of sedentary time may

325 include motion devices, observation and other electronic devices specifically designed to

326 measure ST. Subjective measures rely on self-report, or proxy reporting by a third party

327 (usually a parent). Researchers and practitioners need to consider the type of measurement 
328 instrument, the purpose, the intended outcomes, and a host of practical considerations when

329 selecting the instrument(s) which best suit their needs.

330

\section{$331 \quad$ Practical implications}

332 Accurate assessment of sedentary behavior in youth is necessary to:

333 - determine prevalence and trends

334 - examine associations with health outcomes

335 - identify correlates, determinants, potential mediators and

336 - evaluate the effectiveness of interventions.

\section{Acknowledgments}

339 Preparation for this guide was funded by The Australasian Child and Adolescent Obesity

340 Research Network (ACAORN) (http://sydney.edu.au/medicine/acaorn). Dylan Cliff is funded

341 by a National Heart Foundation of Australia - Macquarie Postdoctoral Research Fellowship

342 (PH 09S 4603). Anna Timperio is supported by a VicHealth Public Health Research

343 Fellowship. 
(1) Pate RR, Mitchell JA, Byun W, et al Sedentary behaviour in youth. Br J Sports Med 2011;45:906-913.

(2) Belanger M, Foster C. Worldwide prevalence of physical inactivity calls for worldwide actions. Prev Med 2011;53:29-30.

(3) Blair SN. Physical inactivity: the biggest public health problem of the 21 st century. $\mathrm{Br}$ J Sports Med 2009;43:1-2.

(4) Janssen I, Leblanc AG. Systematic review of the health benefits of physical activity and fitness in school-aged children and youth. Int J Behav Nutr Phys Act 2010;7:40.

(5) Martinez-Gomez D, Eisenmann JC, Gomez-Martinez S, et al Sedentary behavior, adiposity and cardiovascular risk factors in adolescents. The AFINOS study. Rev Esp Cardiol 2010;63:277-285.

(6) Tremblay MS, Leblanc AG, Kho ME et al. Systematic review of sedentary behaviour and health indicators in school-aged children and youth. Int $J$ Behav Nutr Phys Act 2011;8:98.

(7) Yates T, Wilmot EG, Davies MJ et al. Sedentary behavior: what's in a definition? Am J Prev Med 2011;40:e33-e34.

(8) Biddle SJ, Pearson N, Ross GM, et al. Tracking of sedentary behaviours of young people: a systematic review. Prev Med 2010;51:345-351.

(9) Biddle SJ. Sedentary behavior. Am J Prev Med 2007;33:502-504.

(10) Pate RR, O'Neill JR, Lobelo F. The evolving definition of "sedentary". Exerc Sport Sci Rev 2008;36:173-178.

(11) Dunstan DW, Barr EL, Healy GN et al. Television viewing time and mortality: the Australian Diabetes, Obesity and Lifestyle Study (AusDiab). Circulation 2010;121:384-391.

(12) Healy GN, Matthews CE, Dunstan DW, et al Sedentary time and cardio-metabolic biomarkers in US adults: NHANES 2003-06. Eur Heart J 2011;32:590-597.

(13) Ainsworth BE, Haskell WL, Whitt MC et al. Compendium of physical activities: an update of activity codes and MET intensities. Med Sci Sports Exerc 2000;32:S498S504.

(14) Larson RW, Verma S. How children and adolescents spend time across the world: work, play, and developmental opportunities. Psychol Bull 1999;125:701-736.

(15) Bryant MJ, Lucove JC, Evenson KR, , et al. Measurement of television viewing in children and adolescents: a systematic review. Obes Rev 2007;8:197-209.

(16) Lubans DR, Hesketh K, Cliff DP et al. A systematic review of the validity and reliability of sedentary behaviour measures used with children and adolescents. Obes Rev 2011;12:781-799. 
(17) Ekelund U, Anderssen SA, Froberg K, , et al. Independent associations of physical activity and cardiorespiratory fitness with metabolic risk factors in children: the European youth heart study. Diabetologia 2007;50:1832-1840.

(18) Hardy LL, Dobbins TA, Denney-Wilson E, , et al. Sedentariness, small-screen recreation, and fitness in youth. Am J Prev Med 2009;36:120-125.

(19) Hardy LL, Denney-Wilson E, Thrift AP, , et al. Screen time and metabolic risk factors among adolescents. Arch Pediatr Adolesc Med 2010;164:643-649.

(20) Chinapaw MJ, Proper KI, Brug J, , et al. Relationship between young peoples' sedentary behaviour and biomedical health indicators: a systematic review of prospective studies. Obes Rev 2011;12:e621-e632.

(21) Must A, Tybor DJ. Physical activity and sedentary behavior: a review of longitudinal studies of weight and adiposity in youth. Int J Obes (Lond) 2005;29 Suppl 2:S84-S96.

(22) Marshall SJ, Ramirez E. Reducing sedentary behavior: a new paradigm in physical activity promotion. American Journal of Lifestyle Medicine 2011;5:518-530.

(23) Salmon J, Tremblay MS, Marshall SJ, , et al. Health risks, correlates, and interventions to reduce sedentary behavior in young people. Am J Prev Med 2011;41:197-206.

(24) Ridgers ND, Salmon J, Ridley K, , et al. Agreement between activPAL and ActiGraph for assessing children's sedentary time. Int J Behav Nutr Phys Act 2012;9:15.

(25) Trost SG, Loprinzi PD, Moore R, , et al. Comparison of accelerometer cut points for predicting activity intensity in youth. Med Sci Sports Exerc 2011;43:1360-1368.

(26) Owen N, Healy GN, Matthews CE, et al. Too much sitting: the population health science of sedentary behavior. Exerc Sport Sci Rev 2010;38:105-113. 
Table 1 Key attributes of common methods for measuring sedentary behavior among young people.

\begin{tabular}{|c|c|c|c|c|c|c|c|}
\hline \multirow[b]{2}{*}{ Characteristic } & \multirow[b]{2}{*}{ Accelerometers } & \multicolumn{2}{|c|}{ Objective methods } & \multirow[b]{2}{*}{$\begin{array}{l}\text { Direct } \\
\text { observation }\end{array}$} & \multicolumn{3}{|c|}{ Subjective methods } \\
\hline & & Inclinometers & $\begin{array}{l}\text { Screen } \\
\text { monitoring } \\
\text { devices }\end{array}$ & & Self-report & Parent report & $\begin{array}{l}\text { Time use } \\
\text { Diary/Log }\end{array}$ \\
\hline Population age & $1.5-18$ years & $3-18$ years & $3-18$ years & $3-18$ years & $\geq 12$ years & $1.5-12$ years & ?? 13-18 years \\
\hline Sample size & Small to large & Small to large & Small & Small & Small to large & Small to large & $\begin{array}{l}\text { Small to } \\
\text { medium }\end{array}$ \\
\hline Method & $\begin{array}{l}\text { Prospective/curr } \\
\text { ent. } \\
\text { Monitor usually } \\
\text { worn on a belt } \\
\text { over right hip. }\end{array}$ & $\begin{array}{l}\text { Prospective/curr } \\
\text { ent. } \\
\text { Monitor usually } \\
\text { worn on right } \\
\text { thigh using a } \\
\text { strap or } \\
\text { adhesive pads. }\end{array}$ & $\begin{array}{l}\text { Prospective/cur } \\
\text { rent. } \\
\text { Unit attached to } \\
\text { each screen, } \\
\text { e.g. TV, } \\
\text { computer. } \\
\text { Individuals } \\
\text { need to log-in } \\
\text { using unique } \\
\text { codes }\end{array}$ & $\begin{array}{l}\text { Prospective/curre } \\
\text { nt } \\
\text { Naked eye or } \\
\text { video/film } \\
\text { observation. } \\
\text { Electronic } \\
\text { recording forms. } \\
\text { Momentary time- } \\
\text { sampling (e.g., } \\
\text { multiple } 3-15 \text { sec } \\
\text { observations). }\end{array}$ & $\begin{array}{l}\text { Retrospective } \\
\text { recall: } \\
\text { yesterday, } \\
\text { usual week, } \\
\text { past week, etc }\end{array}$ & $\begin{array}{l}\text { Retrospective } \\
\text { recall: } \\
\text { yesterday, usual } \\
\text { week, past } \\
\text { week, etc }\end{array}$ & $\begin{array}{l}\text { Prospective/curr } \\
\text { ent }\end{array}$ \\
\hline $\begin{array}{l}\text { Assessment } \\
\text { time }\end{array}$ & $\begin{array}{l}\text { Typically } 7 \text {-days } \\
\text { to capture } \\
\text { habitual } \\
\text { behavior. }\end{array}$ & $\begin{array}{l}\text { Typically } 7 \text {-days } \\
\text { to capture } \\
\text { habitual } \\
\text { behavior. }\end{array}$ & $\begin{array}{l}\text { Variable (from } \\
\text { one day to } \\
\text { several weeks) }\end{array}$ & $\begin{array}{l}\text { Variable (from } \\
\text { one to multiple } \\
\text { days) }\end{array}$ & One-off & One-off & $\begin{array}{l}\text { Typically 7-days } \\
\text { to capture } \\
\text { habitual } \\
\text { behavior. }\end{array}$ \\
\hline Data output & $\begin{array}{l}\text { Counts body } \\
\text { movement } \\
\text { (accelerations) in } \\
\text { real time; } \\
\text { algorithms used } \\
\text { to convert to } \\
\text { durations of less } \\
\text { than a user- } \\
\text { identified }\end{array}$ & $\begin{array}{l}\text { Time spent in } \\
\text { different } \\
\text { postures, } \\
\text { including sitting, } \\
\text { in real time. } \\
\text { Number of sit- } \\
\text { to-stand } \\
\text { transitions. } \\
\text { Bouts of sitting }\end{array}$ & $\begin{array}{l}\text { Total time spent } \\
\text { viewing } \\
\text { electronic } \\
\text { screen for each } \\
\text { individual code } \\
\text { over monitoring } \\
\text { period (e.g. } 1 \\
\text { week). }\end{array}$ & $\begin{array}{l}\text { Time spent in } \\
\text { different } \\
\text { postures/intensiti } \\
\text { es, including } \\
\text { sitting/sedentary. }\end{array}$ & $\begin{array}{l}\text { Average } \\
\text { frequency } \\
\text { and/or duration } \\
\text { of overall sitting, } \\
\text { or of specific } \\
\text { sedentary } \\
\text { behaviours. } \\
\text { Weekday and } \\
\text { weekend days }\end{array}$ & $\begin{array}{l}\text { Average } \\
\text { frequency } \\
\text { and/or duration } \\
\text { of overall sitting, } \\
\text { or of specific } \\
\text { sedentary } \\
\text { behaviours. } \\
\text { Weekday and } \\
\text { weekend days }\end{array}$ & $\begin{array}{l}\text { Minutes spent } \\
\text { in specific } \\
\text { behaviours in } \\
\text { 'real-time'. }\end{array}$ \\
\hline
\end{tabular}




\begin{tabular}{|c|c|c|c|c|c|c|c|}
\hline \multirow[b]{2}{*}{ Characteristic } & \multirow[b]{2}{*}{ Accelerometers } & \multicolumn{2}{|c|}{ Objective methods } & \multirow[b]{2}{*}{$\begin{array}{l}\text { Direct } \\
\text { observation }\end{array}$} & \multicolumn{3}{|c|}{ Subjective methods } \\
\hline & & Inclinometers & $\begin{array}{l}\text { Screen } \\
\text { monitoring } \\
\text { devices }\end{array}$ & & Self-report & Parent report & $\begin{array}{l}\text { Time use } \\
\text { Diary/Log }\end{array}$ \\
\hline & $\begin{array}{l}\text { cutpoint to } \\
\text { indicate the } \\
\text { upper limit of } \\
\text { 'sedentary' }\end{array}$ & time. & & & $\begin{array}{l}\text { usually asked } \\
\text { separately. Can } \\
\text { provide context } \\
\text { specific } \\
\text { information }\end{array}$ & $\begin{array}{l}\text { usually asked } \\
\text { separately. Can } \\
\text { provide context } \\
\text { specific } \\
\text { information }\end{array}$ & \\
\hline $\begin{array}{l}\text { Data entry and } \\
\text { data reduction } \\
\text { complexity }\end{array}$ & $\begin{array}{l}\text { High - data } \\
\text { downloaded to } \\
\text { computer and } \\
\text { reduced using } \\
\text { specialised } \\
\text { software }\end{array}$ & $\begin{array}{l}\text { High - data } \\
\text { downloaded to } \\
\text { computer and } \\
\text { reduced using } \\
\text { proprietary } \\
\text { software }\end{array}$ & $\begin{array}{l}\text { Low - Data } \\
\text { recorded by } \\
\text { device }\end{array}$ & $\begin{array}{l}\text { Low - Manual } \\
\text { data entry }\end{array}$ & $\begin{array}{l}\text { Low - manual } \\
\text { data entry or } \\
\text { scanned entry }\end{array}$ & $\begin{array}{l}\text { Low - manual } \\
\text { data entry or } \\
\text { scanned entry }\end{array}$ & $\begin{array}{l}\text { High- } \\
\text { substantial data } \\
\text { entry and data } \\
\text { reduction } \\
\text { required }\end{array}$ \\
\hline
\end{tabular}


Table 2 Limitations and practical considerations associated with common methods of measuring sedentary behavior among young people

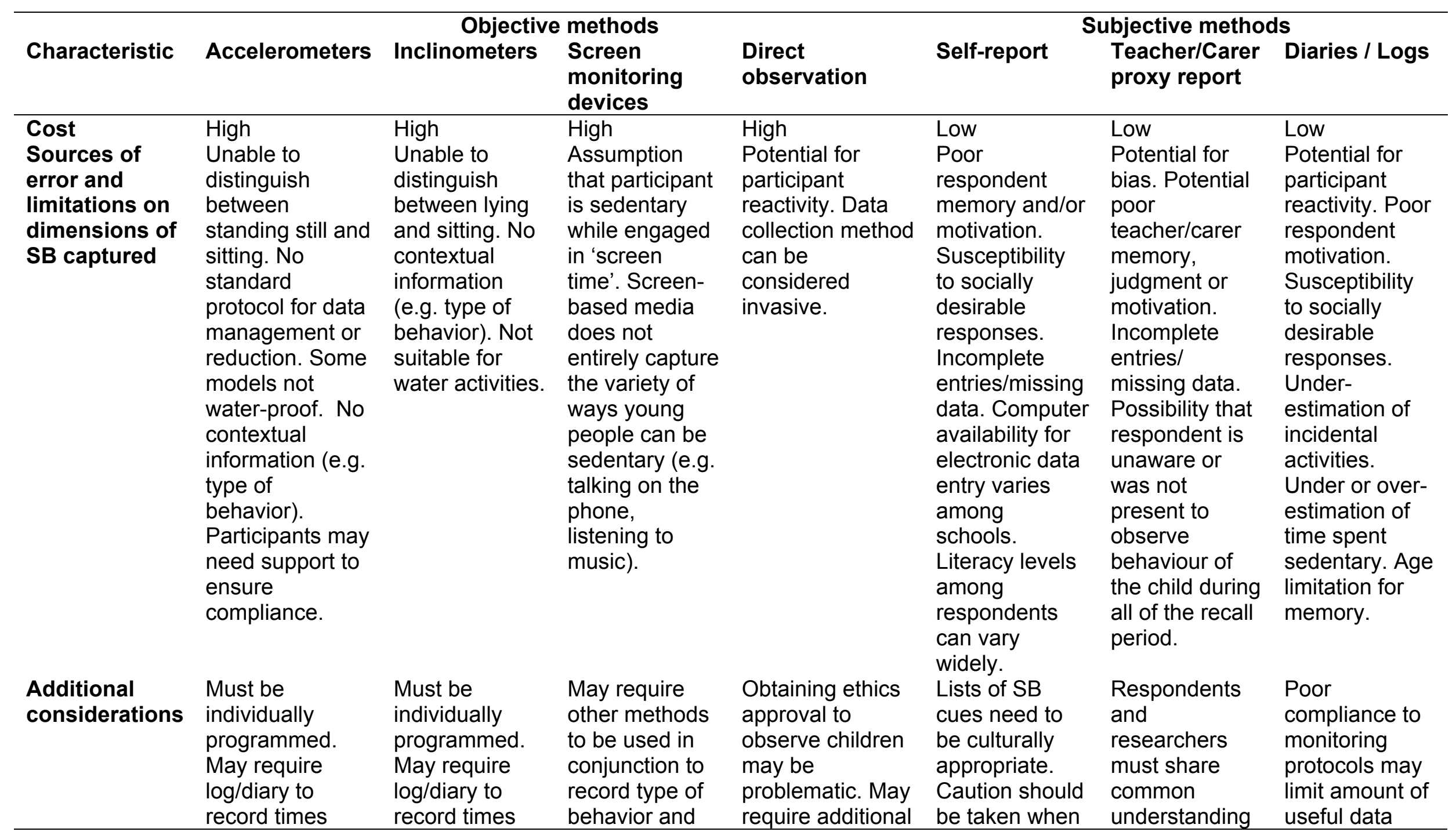




\begin{tabular}{|c|c|c|c|c|c|c|c|}
\hline Characteristic & Accelerometers & \multicolumn{2}{|c|}{ Objective methods } & $\begin{array}{l}\text { Direct } \\
\text { observation }\end{array}$ & \multicolumn{3}{|c|}{ Subjective methods } \\
\hline & $\begin{array}{l}\text { when not worn. } \\
\text { Compliance } \\
\text { issues } \\
\text { (especially } \\
\text { among } \\
\text { adolescents and } \\
\text { obese } \\
\text { participants) can } \\
\text { substantially } \\
\text { reduce final } \\
\text { sample. }\end{array}$ & $\begin{array}{l}\text { when not worn. } \\
\text { Compliance } \\
\text { issues } \\
\text { (especially } \\
\text { among } \\
\text { adolescents } \\
\text { and obese } \\
\text { participants) } \\
\text { can } \\
\text { substantially } \\
\text { reduce final } \\
\text { sample. }\end{array}$ & $\begin{array}{l}\text { posture. } \\
\text { Researchers } \\
\text { required to visit } \\
\text { participants' } \\
\text { homes to } \\
\text { install and } \\
\text { retrieve device. } \\
\text { Each screen } \\
\text { used by } \\
\text { participant } \\
\text { requires a } \\
\text { separate } \\
\text { device. } \\
\text { Parents/child } \\
\text { need to adhere } \\
\text { to protocol of } \\
\text { not sharing } \\
\text { log-ins. }\end{array}$ & $\begin{array}{l}\text { pre-monitoring } \\
\text { period to reduce } \\
\text { participant } \\
\text { reactivity. }\end{array}$ & $\begin{array}{l}\text { estimating total } \\
\text { time spent in } \\
\text { SB due to } \\
\text { young people } \\
\text { engaging in } \\
\text { multiple SB's } \\
\text { simultaneously. }\end{array}$ & $\begin{array}{l}\text { of terms used } \\
\text { (e.g. sedentary } \\
\text { behavior) }\end{array}$ & $\begin{array}{l}\text { and/or the } \\
\text { sample size }\end{array}$ \\
\hline
\end{tabular}




\begin{tabular}{|c|c|c|c|c|c|c|c|}
\hline \multirow[b]{2}{*}{ Characteristic } & \multicolumn{4}{|c|}{ Objective methods } & \multicolumn{3}{|c|}{ Subjective methods } \\
\hline & Accelerometers & Inclinometers & $\begin{array}{l}\text { Screen } \\
\text { monitoring } \\
\text { devices }\end{array}$ & $\begin{array}{l}\text { Direct } \\
\text { observation }\end{array}$ & Self-report & $\begin{array}{l}\text { Teacher/Carer } \\
\text { proxy report }\end{array}$ & Diaries / Logs \\
\hline & & & & & $\begin{array}{l}\text { responses. } \\
\text { Consider use } \\
\text { of pictures / } \\
\text { diagrams to } \\
\text { assist. }\end{array}$ & $\begin{array}{l}\text { respondent is } \\
\text { selected (eg. } \\
\text { the parent that } \\
\text { is home } \\
\text { immediately } \\
\text { after school) }\end{array}$ & $\begin{array}{l}\text { text messages } \\
\text { to parents to } \\
\text { remind children } \\
\text { to complete } \\
\text { diaries (or } \\
\text { direct text } \\
\text { messages to } \\
\text { adolescents). }\end{array}$ \\
\hline
\end{tabular}




\section{Figure Legends}

Figure 1 Decision flow chart to select approaches to measuure sedentary behavior among young people 
Figure 1 Decision flow chart to select approaches to measuure sedentary behavior among young people

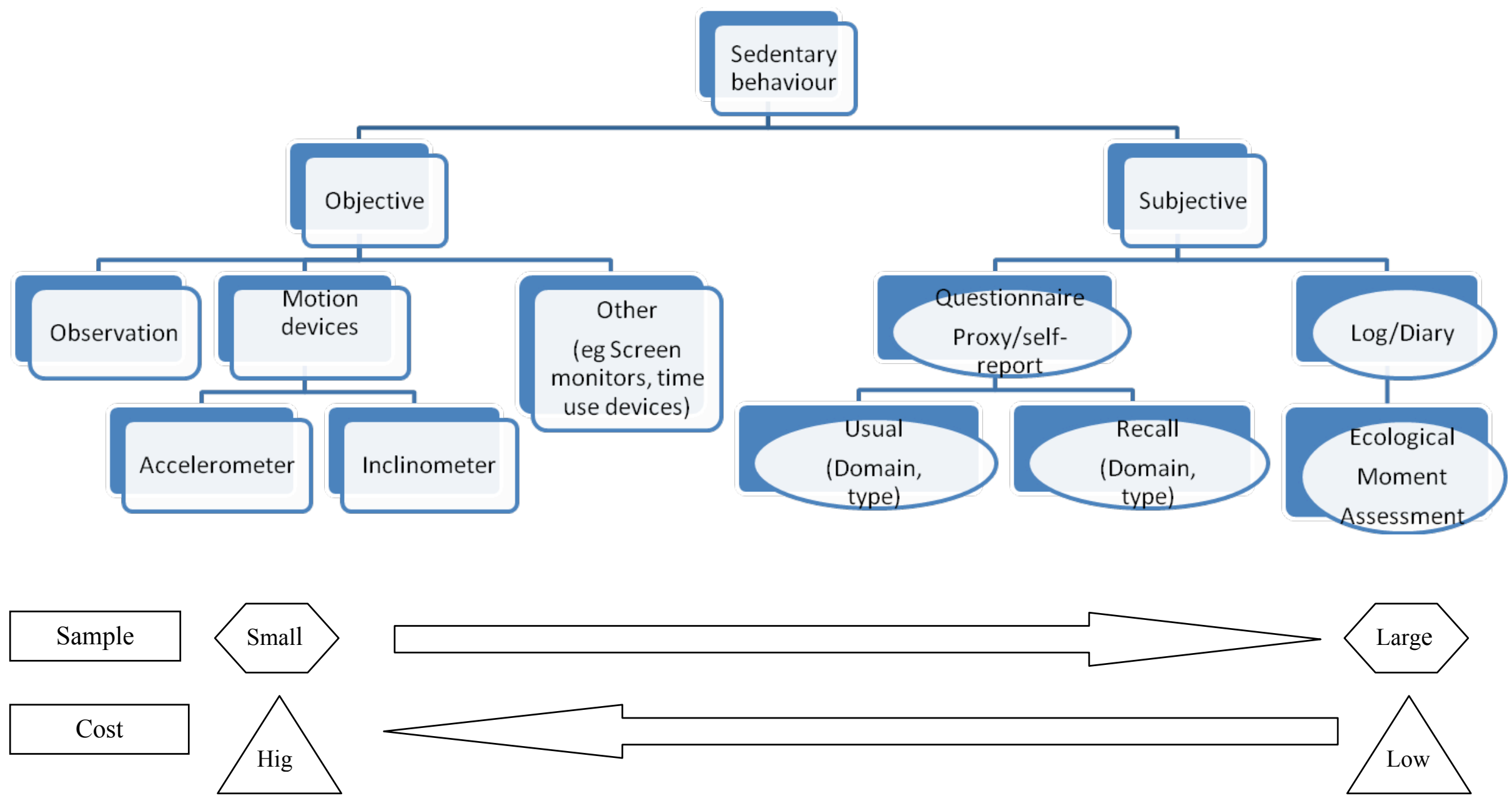

